University of Nebraska - Lincoln

DigitalCommons@University of Nebraska - Lincoln

2018

Seroprevalence Survey for Microsporidia in Common Bottlenose Dolphin (Tursiops truncatus): Example of a Quantitative Approach Based on Immunoblotting

Guillaume Desoubeaux

Roman Peschke

Carolina Le-Bert

Venessa Fravel

Jeny Soto

See next page for additional authors

Follow this and additional works at: https://digitalcommons.unl.edu/usnavyresearch

This Article is brought to you for free and open access by the U.S. Department of Defense at

DigitalCommons@University of Nebraska - Lincoln. It has been accepted for inclusion in U.S. Navy Research by an authorized administrator of DigitalCommons@University of Nebraska - Lincoln. 


\section{Authors}

Guillaume Desoubeaux, Roman Peschke, Carolina Le-Bert, Venessa Fravel, Jeny Soto, Eric D. Jensen, Jennifer E. Flower, Randall Wells, Anja Joachim, and Carolyn Cray 


\title{
Seroprevalence Survey for Microsporidia in Common Bottlenose Dolphin (Tursiops truncatus): Example of a Quantitative Approach Based on Immunoblotting
}

\begin{abstract}
Guillaume Desoubeaux, ${ }^{1,2,3}$ Roman Peschke, ${ }^{4}$ Carolina Le-Bert, ${ }^{5}$ Vanessa Fravel, ${ }^{6}$ Jeny Soto, ${ }^{1}$ Eric D. Jensen, ${ }^{7}$ Jennifer E. Flower, ${ }^{8}$ Randall Wells, ${ }^{9}$ Anja Joachim, ${ }^{4}$ and Carolyn Cray ${ }^{1,10} \quad{ }^{1}$ Division of Comparative Pathology, Department of Pathology \& Laboratory Medicine, Miller School of Medicine, University of Miami, $1600 \mathrm{NW}$ 10th Avenue \#7101A, Miami, Florida 33136, USA; ${ }^{2}$ Service de Parasitologie-Mycologie-Médecine Tropicale, CHU de Tours, 2 Boulevard Tonnellé, Tours 37044, France; ${ }^{3}$ CEPR-INSERM U1100/Équipe 3, Faculté de Médecine, Université François-Rabelais, 10 Boulevard Tonnellé, Tours 37032, France; ${ }^{4}$ Institute of Parasitology, Department of Pathobiology, University of Veterinary Medicine Vienna, Veterinärpl. 1, Vienna 1210, Austria; ${ }^{5}$ National Marine Mammal Foundation, 2240 Shelter Island Drive, Suite 200, San Diego, California 92106, USA; ${ }^{6}$ Six Flags Discovery Kingdom, 1001 Fairgrounds Drive, Vallejo, California 94589, USA; ${ }^{7}$ US Navy Marine Mammal Program, Space and Naval Warfare Systems Center Pacific, 53560 Hull Street, San Diego, California 92152, USA; ${ }^{8}$ Mystic Aquarium, a division of Sea Research Foundation Inc., 55 Coogan Boulevard, Mystic, Connecticut 06355, USA; ${ }^{9}$ Chicago Zoological Society's Sarasota Dolphin Research Program, c/o Mote Marine Laboratory, 1600 Ken Thompson Parkway, Sarasota, Florida 34236, USA; ${ }^{10}$ Corresponding author (email: ccray@med.miami.edu)
\end{abstract}

ABSTRACT: Little is known about microsporidiosis pathogenicity in cetaceans. Here we report seroprevalence of $76 \%$ for microsporidia in blood samples from common bottlenose dolphins (Tursiops truncatus), from animals managed under human care $(n=108)$ or captured for health assessments $(n=13)$ and released.

Microsporidiosis is an opportunistic infection caused by microsporidia, which are unicellular eukaryotes related to fungi (Mathis et al. 2005; Didier and Weiss 2006). It occurs in immunocompromised patients and is orally transmitted by spores contained in excreta of a wide range of host species (Wasson and Peper 2000; Didier and Weiss 2006). Fourteen microsporidian species have been described in humans, and some are zoonotic pathogens, such as Encephalitozoon cuniculi of rabbits, dogs, and rodents (Wasson and Peper 2000), and Enterocytozoon bieneusi of cats, pigs, and cattle (Mathis et al. 2005). However, very little is known about microsporidia infection in some other animal clades, such as cetaceans. Collection of excreta is difficult in aquatic fauna and even more so in wild fauna. Direct methods of detection do not reflect the actual levels of exposure, because spore shedding is known to be transient (Didier and Weiss 2006). Presence of spores in excreta can also reflect a simple gastrointestinal passage of undigested spores, because microsporidia are readily carried by prey fish, such as Atlantic salmon (Salmo salar), round goby (Neogobius melanostomus), turbot (Scophthalmus maximus), and peacock wrasse (Symphodus tinca) for which up to $43 \%$ are positive (Fayer et al. 2008; Kvach and Winkler 2011). Thus, 20.5\% stools from naturally exposed dolphins are positive by PCR at the time of sampling (Fayer et al. 2008). To indicate global exposure, serological assays for prevalence are considered a useful screening approach that can partly overcome the aforementioned limitations.

We obtained blood samples from common bottlenose dolphins (Tursiops truncatus), either managed under human care $(n=108$; male $=50.5 \%$; mean age $=21 \pm 5 \mathrm{yr}$ ) or freeranging $(n=13$; male $=35.7 \%$; mean age $=12 \pm 3$ yr). Plasma specimens were tested at the University of Miami for antimicrosporidial antibodies by means of an inhouse quantitative immunoblot (Desoubeaux et al. 2017b), using E. cuniculi extract as protein antigens (Künzel et al. 2014), and horseradish peroxidase-conjugated rabbit antibottlenose dolphin $\operatorname{IgG}_{\mathrm{h}+\mathrm{l}}$ (Bethyl, Montgomery, Texas, USA). A global score was calculated as the sum of all the band intensities, estimated by two independent optical assessments, which ranged from 0 to 4 for each of the seven proteins located at $135,75,50,40,30,25$, and 19-20 kDa on the immunoblot strip. Thus, the total was ranked on 28 points as a maximum, 


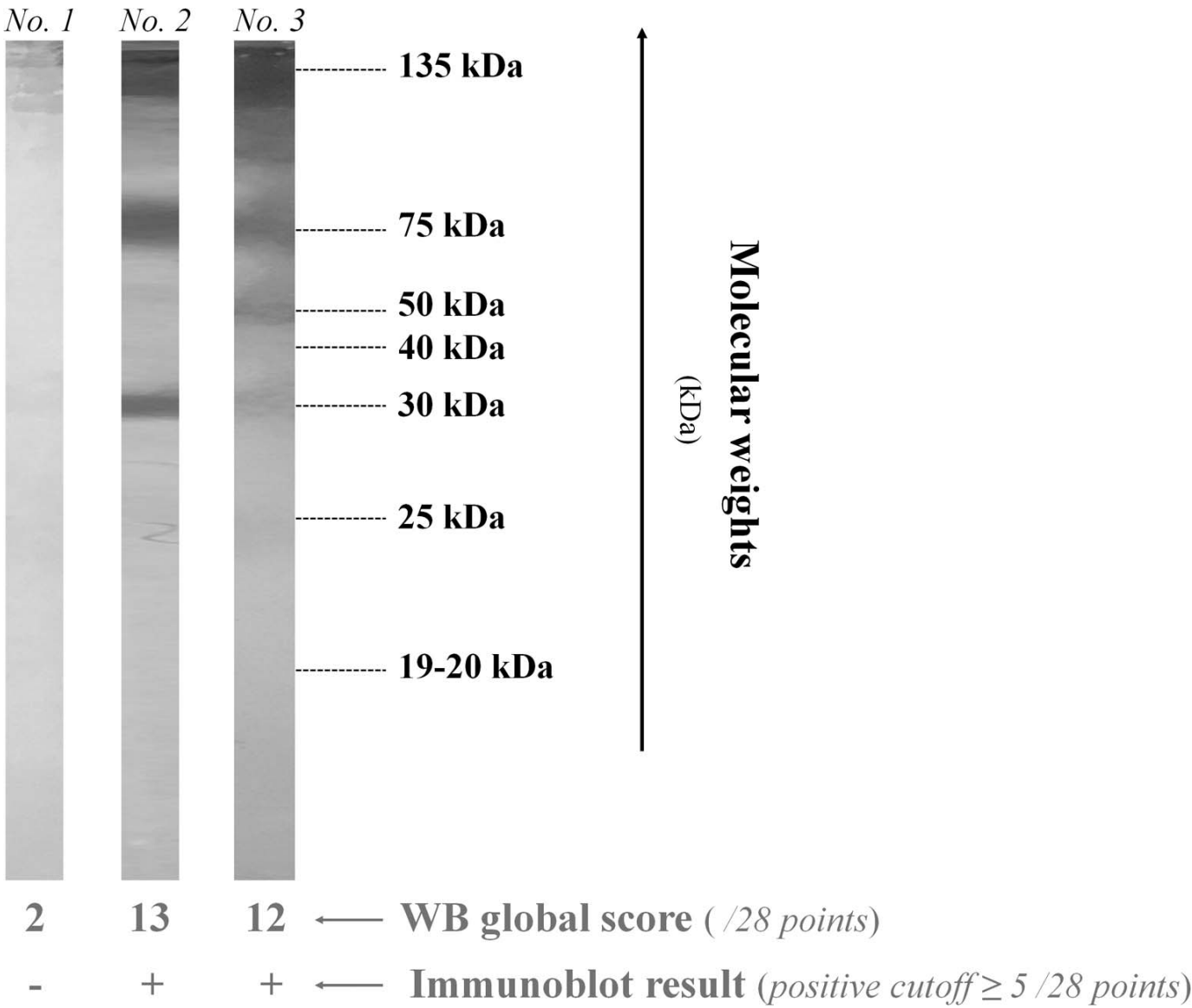

Figure 1. Microsporidial antigen immunoblotting of blood samples from common bottlenose dolphin (Tursiops truncatus). Examples of three plasma specimens showing negative $(-)$ and positive $(+)$ patterns using protein extract from Encephalitozoon cuniculi CH-K 2169 strain (Desoubeaux et al. 2017b) and horseradish peroxidase-conjugated rabbit antibottlenose dolphin $\mathrm{IgG}_{\mathrm{h}+1}$ conjugate. The primary bands are highlighted by the theoretical molecular weight of the corresponding proteins indicated in kilodaltons ( $\mathrm{kDa})$, on the right. In rabbits naturally-infected with E. cuniculi, the polar tube protein 3 (UniProt accession no. Q8MTP3) located at $135 \mathrm{kDa}$ was shown to be the most sensitive, whereas polar tube protein 2 (Q8SRT0) at $30 \mathrm{kDa}$ was found to be statistically associated with the report of current clinical signs (Desoubeaux et al. 2017a). Unlike proteins located at higher molecular weights, immunoreactivity with proteins located at 25 and 19-20 kDa was weak (i.e., positive herein for only $7.9 \%$ and $2.6 \%$ samples, respectively). $\mathrm{WB}=$ western blot.

and the positive cutoff value set at $5 / 28$. In all, $75.9 \%$ samples were positive (Fig. 1). The scores ranged from 0 to $23 / 28$, the median was 8 , and the mean value 9.1 \pm 3.0 . The two proteins located at $135 \mathrm{kDa}$ and $30 \mathrm{kDa}$, corresponding to polar tube protein-3 (UniProt $^{\circledR}$ accession no. Q8MTP3) and polar tube protein-2 (Q8SRT0), showed the highest immunoreactivity, with $71.9 \%$ and $70.2 \%$ positive sera. Specificity of the immune reaction seemed unquestionable, because theoretically, E. cuniculi polar tube protein-3 has peptide sequence similarity only to related proteins of other Encephalitozoon species, such as Encephalitozoon hellem, Encephalitozoon intestinalis, or Encephalitozoon romaleae (identity-threshold $>20 \%$; UniProt BLASTscore $>450$ with 500 hits allowed; UniProt expected value $\leq 1.0 \times 10^{-47}$; https://www. uniprot.org/blast/). Encephalitozoon cuniculi polar tube protein-3 does not share similarities to fungi, bacteria, or archaea. In addition, 
E. cuniculi polar tube protein-2 shares similarity only with Encephalitozoon spp., Vittaforma corneae, Nosema spp., and E. bieneusi (identity-threshold >20\%; UniProt BLASTscore $>125$ with 500 hits allowed; UniProt expected value $\leq 8.4 \times 10^{-5}$ ). There was statistical impact of dolphin sex (odds ratio $=0.50$, $95 \%$ confidence interval $=0.25-0.99 ; P=0.05$ ), but neither of age $(P=0.91)$ nor geographical origin and lifestyle (captive or wild; $P=0.37$ ) upon the overall seroprevalence (using a general linear statistical model of analysis of covariance for measuring association between variables and the immune status ( $\mathrm{Wu} 2018$ ). Associations with the intensity of global antibody score were not significant for all the variables $(P=0.55 ; 0.87$ and 0.94 , respectively)

The hypothesis of an origin of microsporidia contamination by marine species is unlikely: among the various microsporidial species of the fishes eaten by dolphins, none is described as zoonotic. Most microsporidia belong to the clade 5 of Marinosporidia, such as Pleistophora, Tetramicra, Microgemma, and Kabatana genera (Fayer et al. 2008). Thus, environmental contamination with spores of species that come from terrestrial warmblooded animals is more likely. A similar land-to-sea transmission scheme was demonstrated for Toxoplasma gondii, another important pathogenic parasite in various marine mammals (Cooper et al. 2016), where oocysts are excreted by felids, primarily domestic cats (Felis catus), and flushed into coastal waters where they can be ingested directly by susceptible hosts or are concentrated into filtering shellfish which are thereafter eaten (Długońska 2017). Because Toxoplasma seroprevalence is high in dolphins, oocysts have been assumed to get massively collected in the coastal environment through sewage and surface water runoff. For microsporidia, $75.9 \%$ seroprevalence suggested a high level of exposure. Microsporidial spores have been detected in estuaries that collect runoff waters contaminated with feces from terrestrial animals or humans, leaky septic tanks, or wastewater treatment plants, especially after events such as rainfall and sewage overflows.
Likewise, spores have been found in recreational beach waters, mostly observed during weekends and after increased human activities (Graczyk et al. 2010). Infected humans can excrete millions of microsporidia spores daily; a median of $5.0 \times 10^{7}$ spores $/ \mathrm{mL}$ was described in human immunodeficiency virus-positive patient stools (Goodgame et al. 1999), and microsporidia prevalence was found to be up to $60 \%$ in some of domestic terrestrial mammal species ( $\mathrm{Li}$ et al. 2014).

Overall, our serology results indicated a massive exposure to microsporidia in the examined dolphins, but was not able to indicate if the cetaceans are dead-end hosts or if they contribute to the dissemination of the pathogens by excretion. If the latter is true, one could imagine that spores can be dispersed into recreational water for swimming, because dolphins live in coastal waters. Spores could also be readily concentrated in filtering shellfish, such as mussels used for human consumption or as food for other marine mammals (Ghozzi et al. 2017). The pathogenicity of microsporidia in sea mammals is unknown. Around $45 \%$ of the dolphins we studied had undergone routine biopsy or necropsy (for alternative diagnostic investigations in light of clinical signs involving the bowel or the lungs), but no specific histopathological lesions were reported. Neither specific staining nor immunohistochemistry were used to confirm the presence or absence of spores in tissue. Additional studies are now needed in order to determine the in vivo pathological consequences of microsporidia for wildlife health.

We conducted our study using archived samples collected from Six Flags Aquarium and US Navy marine mammals as part of their routine care. The US Navy Marine Mammal Program houses and cares for a population of dolphins in San Diego Bay (California, USA). The Marine Mammal Program is accredited by the Association for Assessment and Accreditation of Laboratory Animal Care and adheres to the national standards of the US Public Health Service Policy on the Humane Care and Use of Laboratory Animals and the Animal Welfare Act. Samples obtained from 
free ranging dolphins in Sarasota Bay (Florida, USA) were collected under National Marine Fisheries Service Scientific Research Permit 15543 and Mote Marine Laboratory Institutional Animal Care and Use Committees approval, with support from Dolphin Quest, Inc., the Chicago Zoological Society, and the Office of Naval Research.

\section{LITERATURE CITED}

Cooper MK, Phalen DN, Donahoe SL, Rose K, Šlapeta J. 2016. The utility of diversity profiling using Illumina $18 \mathrm{~S}$ rRNA gene amplicon deep sequencing to detect and discriminate Toxoplasma gondii among the cystforming coccidia. Vet Parasitol 216:38-45.

Desoubeaux G, Del Carmen Piqueras M, Pantin A, Bhattacharya SK, Peschke R, Joachim A, Cray C. 2017a. Application of mass spectrometry to elucidate the pathophysiology of Encephalitozoon cuniculi infection in rabbits. PLoS One 12:e177961.

Desoubeaux G, Pantin A, Peschke R, Joachim A, Cray C. 2017b. Application of western blot analysis for the diagnosis of Encephalitozoon cuniculi infection in rabbits: Example of a quantitative approach. Parasitol Res 116:743-750.

Didier ES, Weiss LM. 2006. Microsporidiosis: Current status. Curr Opin Infect Dis 19:485-492.

Długońska H. 2017. Are poikilothermic animals real hosts for Toxoplasma gondii? Ann Parasitol 63:3-5.

Fayer R, Fair PA, Bossart GD, Santín M. 2008. Examination of naturally exposed bottlenose dolphins (Tursiops truncatus) for Microsporidia, Cryptosporidium, and Giardia. J Parasitol 94:143-147.

Ghozzi K, Marangi M, Papini R, Lahmar I, Challouf R, Houas N, Dhiab RB, Normanno G, Babba H, Giangaspero A. 2017. First report of Tunisian coastal water contamination by protozoan parasites using mollusk bivalves as biological indicators. Mar Pollut Bull 117:197-202.

Goodgame R, Stager C, Marcantel B, Alcocer E, Segura AM. 1999. Intensity of infection in AIDS-related intestinal microsporidiosis. J Infect Dis 180:929 932.

Graczyk TK, Sunderland D, Awantang GN, Mashinski Y, Lucy FE, Graczyk Z, Chomicz L, Breysse PN. 2010. Relationships among bather density, levels of human waterborne pathogens, and fecal coliform counts in marine recreational beach water. Parasitol Res 106: 1103-1108

Künzel F, Peschke R, Tichy A, Joachim A. 2014. Comparison of an indirect fluorescent antibody test with western blot for the detection of serum antibodies against Encephalitozoon cuniculi in cats. Parasitol Res 113:4457-4462.

Kvach Y, Winkler HM. 2011. The colonization of the invasive round goby Neogobius melanostomus by parasites in new localities in the southwestern Baltic Sea. Parasitol Res 109:769-780.

Li W, Li Y, Li W, Yang J, Song M, Diao R, Jia H, Lu Y, Zheng J, Zhang X, et al. 2014. Genotypes of Enterocytozoon bieneusi in livestock in China: High prevalence and zoonotic potential. PLoS One 9: e97623.

Mathis A, Weber R, Deplazes P. 2005. Zoonotic potential of the microsporidia. Clin Microbiol Rev 18:423-445.

Wasson K, Peper RL. 2000. Mammalian microsporidiosis. Vet Pathol 37:113-128.

$\mathrm{Wu}$ H. 2018. Approximations to the distribution of a test statistic in covariance structure analysis: A comprehensive study. Br J Math Stat Psychol 71:334-362.

Submitted for publication 28 November 2017.

Accepted 15 February 2018. 